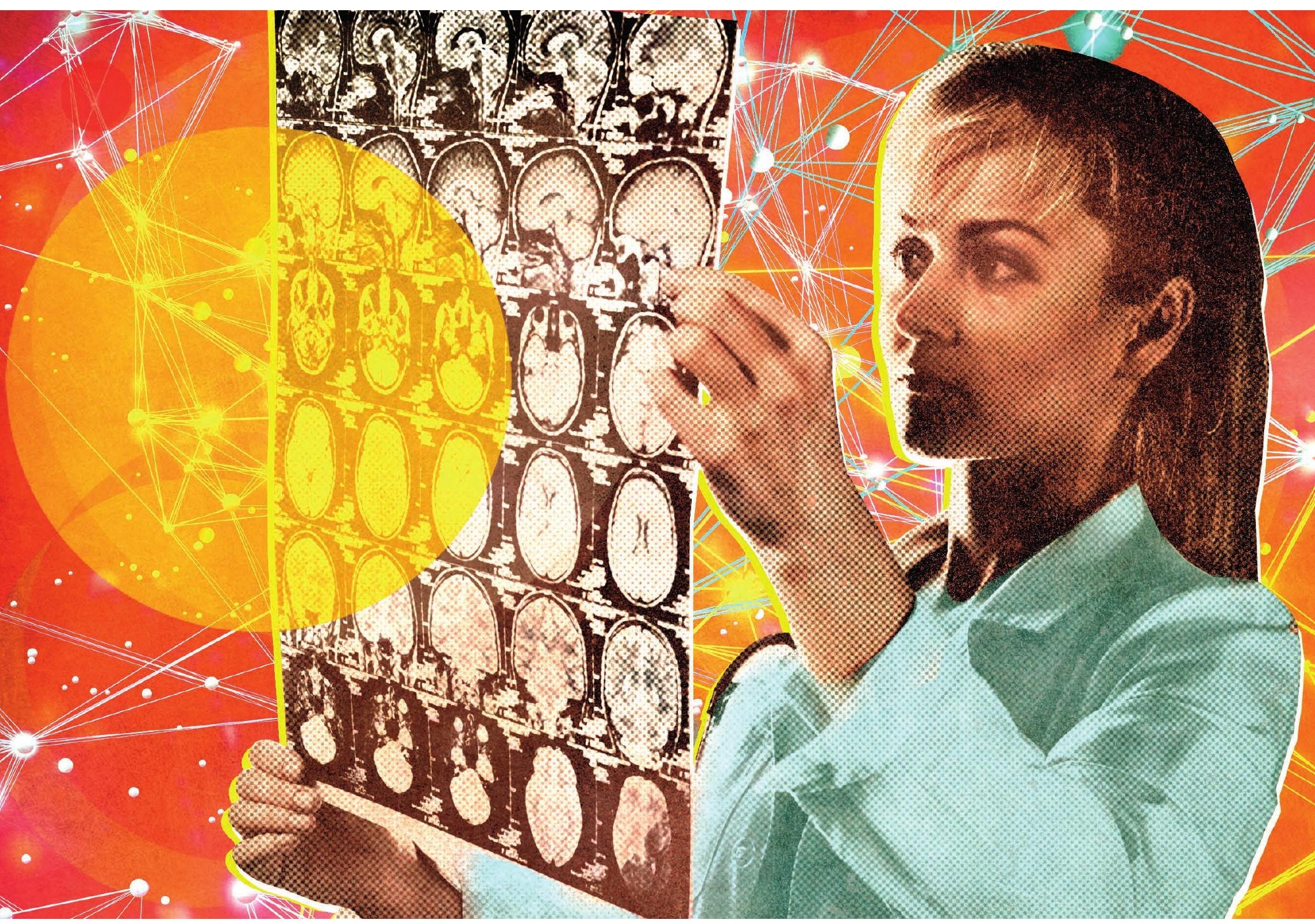

\title{
Neuroscience starts talking
}

The previously introverted discipline is opening up to collaboration.

BY ANDREW CURRY

$\mathrm{I}$ n late 2015, tens of thousands of refugees were arriving in Germany each month, fleeing conflict in Syria and elsewhere sparked in part by the 'Arab Spring', the series of protests across North Africa and the Middle East that began in 2010 .

Neurologists Tomás Goucha and Alfred Anwander wanted to help: their colleagues at o the Max Planck Institute for Human Cognitive and Brain Sciences in Leipzig, Germany, were collecting used clothes, volunteering at refugee centres and teaching new arrivals German. The two researchers thought that there must be a more targeted way to use their skills, and wondered whether the crisis might provide an opportunity to examine key questions about how the brain learns language - while offering the refugees a vital tool to help them to integrate into German society.

How people acquire a second language is notoriously tricky to study, because language learners typically come from a variety of backgrounds and have different mother tongues. On top of that, any useful study would have to involve linguists, physicists, language teachers, neuroscientists and dozens of motivated learners. "A lot of people around me prefer not to do interdisciplinary work," Goucha says. "It's easier to have simple experiments, but often they completely miss the point."

Fortunately for Goucha and Anwander and their study cohort, neuroscience is getting better at collaborating. From linguistics to psychology, biology and anthropology, neuroscientists are finding ways to collaborate with disciplines in ways that advance knowledge - and scientific careers. "Many institutions in the past worked in isolation," says psychiatrist Natalie Rasgon at Stanford University in California, "but now there's close collaboration and it's incredibly encouraging."

With funding from their department at the Max Planck Institute, which was already focused on the neuroscience of language acquisition, Goucha and Anwander contacted the University of Leipzig's Herder Institute, which teaches German as a foreign language. They recruited 90 Syrian refugees interested in 
> learning the language, and worked closely with language teachers on the experiment's design. Beginning in May 2016, half of the students were taught in a way that initially emphasized vocabulary, while the other half were taught in a grammar- and syntax-heavy style that introduced complex sentences earlier in the course.

One of the goals of the study was to identify whether people learning a second language as adults use the parts of the brain usually associated with speech and language in their mother tongue, and what connections in other parts of the brain are activated. At three-month intervals over the course of one year, the Syrian students were scanned in magnetic resonance imaging (MRI) machines while listening to German-language prompts - sentences with incorrect word order, for example - designed to test their knowledge of grammar and vocabulary. A group of native German speakers was scanned as a control.

"In the end, the refugee crisis posed a huge challenge to integration, and this cohort was a unique opportunity to investigate it," says Goucha.

\section{OPEN ARMS}

Many senior scientists say that it's especially important for early-career researchers interested in interdisciplinary work to familiarize themselves with the key questions being asked elsewhere. "Unless you learn early to communicate with other disciplines, it will be harder later to do cutting-edge science, which is often interdisciplinary," says Angela Friederici, director of the neuropsychology department at the Max Planck Institute for Human Cognitive and Brain Sciences and vice-president of the Max Planck Society.

When Friederici was starting her career in linguistics and psychology, "interdisciplinary work was not on the screen”, she says. Neuroimaging tools weren't available, and researchers based hypotheses about how the brain worked on observations of people with brain damage.

Even after functional MRI data gave scientists a way to directly observe activity in the brain in the early 1990s, neuroscientists struggled to use the tool effectively. "Scientists put people in the scanner and told them to think about God, and then interpreted the activated region as 'the God area," Friederici says. "Now we do very systematic studies: we ask a specific question, and get a specific brain answer."

And as the questions neuroscientists ask get more precise - and neuroscience itself becomes more complex and specialized - meaningful collaboration with other disciplines is increasingly necessary.

It hasn't been easy: when working with translational scientists such as psychologists and clinicians, neuroscientists have often had to overcome their colleagues' deeply held scepticism - a wariness stemming from a sense that the field has over-promised and under-delivered. Collaborations with clinicians rarely result in findings that can directly translate to patient care, for example. "It's fair to say the field is still waiting for evidence from neuroimaging that really makes a difference in clinical-service provision," says Ulrich Schnyder, a psychiatrist at the University of Zurich in Switzerland. "There's lots of interesting evidence coming out of these studies, but the benefit for patients is very limited. My experience is that it's always disappointing."

Despite this, Schnyder decided earlier this year to take a chance. With colleagues at the University of Zurich, he helped to launch a project designed to test whether the effects of psychological trauma can be inherited. The work is based on research by Isabelle Mansuy, a neuroepigeneticist at the university. Her work shows that the offspring of traumatized mice behave differently from their peers, displaying the rodent equivalent of anxiety and depression ${ }^{1}$. "We know it's epigenetic, not social," Mansuy says. Even mice born in vitro, conceived with the sperm of traumatized males but fostered by unaffected mothers, behaved differently.

\section{UNLESS YOU LEARN EARLY TO COMMUNICATE WITH OTHER DISCIPLINES, IT WILL BE HARDER LATER TO DO CUTTING-EDGE SCIENCE.}

By tracking genetic markers in the mice, Mansuy has been able to show why. Trauma alters the DNA and RNA of blood, sperm and brain cells of lab mice. She anticipates that the results will help clinicians to understand how trauma is passed from generation to generation in people. "The hope is that some of the same genes altered in mice will be affected in humans," she says. "We're trying to identify the mechanisms by which environmental factors or personal experience influence mental or physical health across generations."

Translating her results to humans, Mansuy admits, is a tall order. "You need an extremely solid mouse model and to find the right collaborators," she says. "It took years to collect enough evidence for the concept to be valid." After 15 years of research, Mansuy approached Schnyder and his University of Zurich colleague, psychologist Monique Pfaltz, suggesting that they collaborate to see whether there was evidence of similar phenomena in humans.
Persuading Schnyder, Pfaltz and other clinical researchers to work with her was time-consuming. "It's not been easy finding clinicians who have the mindset and time. They need to be convinced that the effort they are going to put into this is valid," Mansuy says. "You need to assemble large cohorts in a rigorous manner, apply for an ethics permit - there are many technical details which are difficult to set up. It requires will from both parties." Over the next few years, Mansuy and Pfaltz will search for evidence of epigenetic changes in blood samples from people who experienced psychological trauma during their childhood.

\section{JOINING THE DOTS}

Other groups are taking a close look at the interactions between body and brain. Researchers have documented immune-system reactions that can cause mental illness, and there's evidence that the gut microbiota - a teeming mass of trillions of bacteria - can influence brain structure and function, potentially having a role in everything from food cravings to depression.

Endocrinology, the study of the body's hormone system, is also an area where neurologists have an increasingly important role. Rasgon, for instance, has focused on understanding why diabetes is associated with dramatically increased risk for neurological problems such as depression and dementia.

Yet until a few years ago, Rasgon struggled to find funding for collaborative projects. For example, the US National Institute of Diabetes and Digestive and Kidney Diseases (NIDDK) in Bethesda, Maryland, a division of the National Institutes of Health (NIH), repeatedly turned down her applications for funding to look at the links between insulin resistance - a key risk factor for diabetes - and neurological issues.

Then, in 2012, the NIDDK and several other NIH divisions hosted a meeting that brought people from the diabetes research community together with scientists investigating depression and dementia. The meeting paved the way for a large-scale effort to examine the links between insulin resistance and disorders of the central nervous system. Dubbed PALS (Psychopathology and Allostatic load across the Life Span), the project launched earlier this year, and involves institutions in five countries. Group members range from the Rockefeller University in New York City to Vrije University in Amsterdam.

Carefully defining the parameters of the collaboration was crucial. "The concept is universal, but the focus remains narrow," Rasgon says. "That keeps the neuroscientists from going too crazy with the idea that it goes too far from brain research, but it also keeps the endocrinologists interested."

For an early-career neuroscientist, the added challenges of organizing an ambitious collaboration can be discouraging. Some of the reluctance is understandable. "People tend to over-specialize," says Goucha. "Trying to find 
common vocabulary to talk with the other side, find common interests and establish a dialogue is very time-consuming and probably not the most effective way of getting a lot of papers published within a year."

\section{NEW TOOLS}

Even fields rarely connected to neuroscience, such as anthropology, are yielding fruitful examples of collaboration - and attracting much attention, from media coverage to publication in leading journals.

An enduring debate in anthropology is whether language was needed to make the complex stone tools that started appearing about one million years ago. When Shelby Putt - at the time an anthropology $\mathrm{PhD}$ student at the University of Iowa in Iowa City - decided to devote her dissertation to the question, the idea of working with a neuroscientist was daunting. "At first it was purely experimental archaeology, with no neuroscience component," she says.

Putt's adviser pointed her to a lab at the university that used a new technique - called functional near-infrared spectroscopy (fNIRS) - that is capable of monitoring brain activity during physical activity (unlike functional MRI, which requires people to lie still in a large scanner). "I sent them a proposal, and I remember one postdoc chuckling at some of the things I wanted to do," Putt says.

Neuroscientist John Spencer, who had recently taken over the university's ANIRS facility and was looking for interdisciplinary opportunities, agreed to give Putt a chance. "They were willing to take me on," Putt says. "I ended up learning a lot."

With Spencer's guidance, Putt asked dozens of volunteers to watch multiple videos of an expert stone toolmaker crafting flint hand axes. One group heard the craftsman giving instructions; another group watched without audio. Later, wearing an fNIRS cap resembling a hairnet, participants were asked to make the tools themselves. As they worked, researchers noted which parts of the brain were activated - and whether these differed between participants who recieved language clues and those that did not. The results showed that crafting the advanced tool was closely linked not to language centres, but to the parts of the brain responsible for activities such as playing music.

After four years of experiments, Putt and Spencer published their first results earlier this year ${ }^{2}$. Putt, now a postdoc at the Stone Age Institute and at the Center for Research into the Anthropological Foundations of Technology at Indiana University, Bloomington, credits Spencer, now at the University of East Anglia, UK, for taking a gamble on her. "A lot of respect to him for taking an anthropologist on."

\section{BETTER COMMUNICATION}

Some neuroscientists are reaching even farther afield, using insights from the study of the brain to inform how science is communicated.
Neuroscientist Tedi Asher's doctoral research at Harvard Medical School in Boston, Massachusetts, involved studying the neurons responsible for making the neurotransmitter serotonin. After earning her $\mathrm{PhD}$, Asher was hired by the Peabody Essex Museum in Salem, Massachusetts, as the museum's first neuroscience researcher. "The museum director thought if we're going to create experiences for visitors that are memorable, it would be good to understand what's going on in the brain," she says.

Asher scours neuroscience literature for studies that offer museum professionals ways to improve the visitor experience - information on how people allocate their attention, or how the structure of the visual system shapes perception. Research showing that memory works better when more than one sense is engaged ${ }^{3}$ prompted the museum to place jars of spices at the entrance to an exhibit on Asian art to add an olfactory element to the artworks. "I'm working with the curatorial staff to think about how that can inform their work," Asher says. The ultimate goal is a publication that other museums could use to improve exhibit design.

In the past decade, a handful of dedicated programmes designed to provide interdisciplinary education to early-career scientists have been introduced, at institutes from the Center for Mind-Body Research at Johns Hopkins University in Baltimore, Maryland, to the Berlin School of Mind and Brain. In Leipzig, a recently introduced programme for graduate students and postdocs offers crash-course modules in linguistics, social cognition, neuroimaging and psychiatry. "In earlier times, you had to study one discipline after another," says Friederici. "Programmes like these give people the opportunity to learn what the crucial questions are in other disciplines."

Goucha and Anwander, meanwhile, are more than a year into their study of language acquisition. Their preliminary results suggest that people learning a second language rely on parts of the brain that aren't usually associated with language - in particular, the zones devoted to attention and memory.

At the same time, the linguists and language teachers in the group were able to discern differences between the vocabulary-oriented group and the syntax-oriented group that could lead to data-based changes in the way that German is taught. "We decided to go for a broader approach to understand how brain structure changes," says Goucha. "We hope to show not only that the brain changes while learning language - but also to understand how." -

\section{Andrew Curry is a journalist based in Berlin.}

1. Bohacek, J., Weber-Stadlbauer, U. \& Mansuy, I. M. Mol. Psychiatr. http://dx.doi.org/10.1038/ mp.2017.162 (2017).

2. Putt, S. S., Wijeakumar, S., Franciscus, R. G. \& Spencer, J. P. Nature Hum. Behav. 1, 0102 (2017).

3. Kim, R. S., Seitz, A. R. \& Shams, L. PLoS ONE 3, e1532 (2008).

\section{CORRECTION}

The Spotlight article 'Neuroscience starts talking' (Nature 551, S81-S83; 2017) affiliated Tedi Asher with the wrong Peabody Museum. She is, in fact, at the Peabody

Essex Museum in Salem, Massachusetts. 